ISSN 1112-9867

http://www.jfas.info

\title{
EVALUATION OF FATIGUE CRACK GROWTH RATE FOR IRON-CARBON METALS BASED ON DEGRADATION-ENTROPY GENERATION THEOREM
}

\author{
R. Idris, S. Abdullah*, P. Thamburaja and M. Z. Omar \\ Department of Mechanical and Materials Engineering, Faculty of Engineering and Built \\ Environment, UniversitiKebangsaan Malaysia, 43600 Bangi, Selangor, Malaysia
}

Published online: 17 October 2017

\begin{abstract}
This paper presents the evaluation of fatigue crack growth rate for iron-carbon metals based on degradation-entropy generation theorem. The different microstructural phases present in tempered Fe-C steels can influence the fatigue strength. The relationships between entropy and crack propagation are intimately related within the degradation coefficient that could be arrived from consideration of the degradation-entropy generation theorem. To ensure validity, temperature evolution is measured through a fatigue crack growth test induced upon a tempered Fe-C steels material till it fails. Finally, the results of the present model are compared to measured Paris-regime crack growth data, thus arriving at a conclusion that the surface temperature of a specimen under fatigue crack growth test can be used to determine the rate of crack growth by intensity of the degradation coefficient.
\end{abstract}

Keywords: degradation-entropy generation theorem; entropy generation; fatigue crack growth rate; tempered Fe-C steel.

Author Correspondence, e-mail: shahrum@ukm.edu.my

doi: http://dx.doi.org/10.4314/jfas.v9i5s.37 


\section{INTRODUCTION}

Generally, fatigue is the process of crack initiation, propagation and final fracture. The period of cycles for crack propagation starting from initial size until a certain critical size can be defined as fatigue life of the material. Fracture mechanics has made an excellent contribution towards the improvement of fatigue crack propagation prediction since Paris and Erdogan[1] first formulated the empirical relation amongst the crack growth rate, da/dN and the stress intensity factor range, $\Delta \mathrm{K}$ within the stable crack propagation region (Region II). From engineering material point of view, it has been found by other researchers [2-3] that fatigue crack growth (FCG) could be significantly influenced by microstructure contents. As an example, the second hard phase (martensite or bainite) distributed in the soft ferrite matrix can effectively influence FCG through the study of different tempered Fe-C steels.

As stated by the second law of thermodynamics, every dissipative process is followed by an increase in entropy e.g. plasticity, twinning, phase transformation, grain boundary motion [4-5] etc. Entropy production has also been applied as means of measuring component degradation e.g. wear and friction [6] and also damage accumulation due to fatigue. An experimental method to calculate entropy generated during low cycle fatigue for metals was proposed [7] in addition to its theoretical formulation [8]. Furthermore, the crack layer theory has been developed to examine the evolution of damage as well as having the active zone of crack layer under fatigue loading histories along with a crack layer constitutive relationship is obtained [9].

The degradation or aging of a given technique is intimately related to the entropy production that accumulates progressively eventually and degrades the device until its final breakdown. The relationship between degradation and entropy generation created by an accompanying irreversible processes occurring within a system was founded [10]. The driving motivation regarding the creation of the Degradation-Entropy Generation (DEG) theorem is often described as the fundamental understanding that entropy monotonically increases and free energy monotonically decreases for every natural processes understanding that an entropy-generating irreversible process accompanies all aging phenomena. Following the strategy of entropy increase, manufactured organized components turns into their natural conditions through degradation which reduces the integrity of material properties and being 
finally non-functional [11]. However, within the framework of fracture mechanics, the entropy generated from crack propagation is an aspect which has not been thoroughly investigated.

In the present study, the effort is made to show that the fatigue degradation and entropy generation are intimately related so that their relationship should be considered for evaluation of FCG rate based on the degradation-entropy generation theorem, and making fundamental improvement in the research relating to FCG rate without the need to go for traditional techniques that are based on empirical models. The FCG rate was estimated directly from evaluation of the fatigue degradation and entropy generation. The concept of degradation-entropy generation theorem is found to be a reliable way to evaluate the FCG rate.

\section{THEORY-DEGRADATION ENTROPY GENERATION THEOREM}

The concept of degradation forces has been introduced, [10] according to thermodynamic forces to define degradation parameter $w=w\left\{p_{j}\left(\zeta_{j}^{k}\right)\right\}$ as follows:

$$
\frac{d w}{d t}=\sum_{J} \sum_{k}\left(\frac{\partial w}{\partial p_{j}} \frac{\partial p_{j}}{\partial \zeta_{j}^{k}}\right) \frac{\partial \zeta_{j}^{k}}{\partial t}=\sum_{j} \sum_{k} Y_{j}^{k} J_{j}^{k}
$$

with $Y_{j}^{k}$ being the degradation forces. It is to be noted that the degradation of a given system is dependent upon the equivalent dissipative processes $p_{j}$, as does the entropy generation. Given that thermodynamic flow $J_{j}^{k}$ is probably the common parameter in Equation (1), a degradation coefficient might be known as:

$$
B_{j}=\frac{Y_{j}^{k}}{X_{j}^{k}}=\frac{\left(\partial w / \partial p_{j}\right)\left(\partial p_{j} / \partial \zeta_{j}^{k}\right)}{\left(\partial_{i} S / \partial p_{j}\right)\left(\partial p_{j} / \partial \zeta_{j}^{k}\right)}=\left.\frac{\partial w}{\partial_{i} S}\right|_{p_{j}}
$$

where $B_{j}$ in Equation (2) describes how entropy generation and degradation interact with the dissipative processes $p_{j}$.

By assuming that the crack growth occurs at a steady rate, the crack length, $\mathrm{w}=\mathrm{a}$ can be defined as the degradation parameter. Thus, degradation can be denoted as $a=a\left\{W_{p}(N)\right\}$ 
where $\mathrm{W}_{\mathrm{p}}$ is the plastic energy generation at the crack tip and the plastic energy is dissipated as entropy generation i.e. $d W_{p}=T d_{i} S$. Therefore, the entropy generation can be described as:

$$
\sigma=\frac{d_{i} S}{d t}=\frac{\partial_{i} S}{\partial p} \frac{\partial p}{\partial N} \frac{\partial N}{\partial t}=\frac{f}{T} \frac{d W_{p}}{d N}
$$

and the rate of degradation, $\mathrm{D}=\mathrm{dw} / \mathrm{dt}$ can be obtained using the chain rule as:

$$
D=\frac{d w}{d t}=\left(\frac{\partial w}{\partial p} \frac{\partial p}{\partial \zeta}\right) \frac{\partial \zeta}{\partial t}=Y J
$$

where $X=(1 / T)\left(d W_{p} / d N\right)$ and $\mathrm{T}$ is the surface temperature. Since the degradation parameter $\mathrm{w}=\mathrm{a}$, we use Equation (4) and obtain:

$$
D=\frac{d a}{d t}=Y J=B X J=B \frac{f}{T} \frac{d W_{p}}{d N}
$$

The degradation coefficient $\mathrm{B}$ in Equation (5) measures how entropy generation and crack propagation interact on the level of dissipative plastic deformation process.

Methods are developed to assess the energy dissipation in the plastic zone ahead of the crack tip, $\mathrm{W}_{\mathrm{p}}$. Here, we use a correlation presented by [12]:

$$
\frac{d W_{p}}{d N}=A t \frac{(\Delta K)^{4}}{\mu \sigma_{y}^{2}}
$$

where $\mathrm{A}$ is a dimensionless constant, $\mathrm{t}$ the specimen thickness, $\Delta \mathrm{K}$ the stress intensity factor, $\mu$ the shear modulus and $\sigma_{\mathrm{y}}$ the yield stress. Substituting Equation (6) into Equation (5) yields:

$$
\frac{d a}{d N}=\frac{d a}{f d t}=B \frac{A t}{T} \frac{(\Delta K)^{4}}{\mu \sigma_{y}^{2}}=C(\Delta K)^{4}
$$

Equation (7) represents the Paris-Erdogan law of crack propagation with constant $\mathrm{C}$ defined as:

$$
C=B \frac{A t}{T \mu \sigma_{y}^{2}}
$$

Equation (8) signifies the intimate relation between the constant $\mathrm{C}$ in Paris-Erdogan law and degradation coefficient $\mathrm{B}$, which is in turn related to entropy generation. 


\section{METHODOLOGY}

\subsection{Material and Processing}

A low carbon steel sample was used in the present study. This steel was selected because the temperature ranges between Eutectoid temperatures, minimum temperature of austenite, $\mathrm{A}_{1}$ and lower-bound temperature for austenite, $\mathrm{A}_{3}$ in iron-carbon phase diagram are the largest than other types of carbon steel samples. A tempered Fe-C steel is produced by subjecting low carbon steel samples to inter-critical annealing from a temperature above $A_{1}$ but below $A_{3}$ between the two phases (ferrite + austenite) region for a specific duration, and followed by water quenching. The chemical compositions of this steel are shown in Table 1. Two successive heat treatment processes were carried out in order to obtain tempered $\mathrm{Fe}-\mathrm{C}$ material. In the first process, the as-received specimens were annealed at $760{ }^{\circ} \mathrm{C}$ for $90 \mathrm{~min}$, followed by water quenching (inter-critically annealed). This would lead to the formation of the martensitephase. The second process includes a tempering at temperature of $400{ }^{\circ} \mathrm{C}$, holding for 2 hours and cooling at room temperature to form tempered martensite. This tempering temperature was chosen because traditionally, low carbon steel is tempered after heat treatment between $200{ }^{\circ} \mathrm{C}$ and $600{ }^{\circ} \mathrm{C}$ [13-15].

Table 1. Chemical composition of the steel, wt \%

\begin{tabular}{cccccccc}
\hline Elements & $\mathbf{C}$ & $\mathbf{M n}$ & $\mathbf{S i}$ & $\mathbf{P}$ & $\mathbf{S}$ & $\mathbf{A l}$ & $\mathbf{F e}$ \\
\hline wt \% & 0.192 & 1.61 & 0.384 & 0.0162 & 0.0085 & 0.0314 & 97.4 \\
\hline
\end{tabular}

\subsection{Tensile and Fatigue Crack Growth (FCG) Rate Tests}

The tensile specimens were prepared in accordance to ASTM E8 [16] in sub-size dimensions with gauge length of $25 \mathrm{~mm}$ as shown in Fig. 1. Tensile tests were conducted according to ASTM E8 [16] procedures at room temperature using the ZwickRoell universal testing machine with a cross-head speed of $1.8 \mathrm{~mm} / \mathrm{min}$ (which corresponds to strain rate of 0.001 $\mathrm{s}-1)$ to investigate the mechanical properties for the as-received and tempered Fe-C steel samples. 


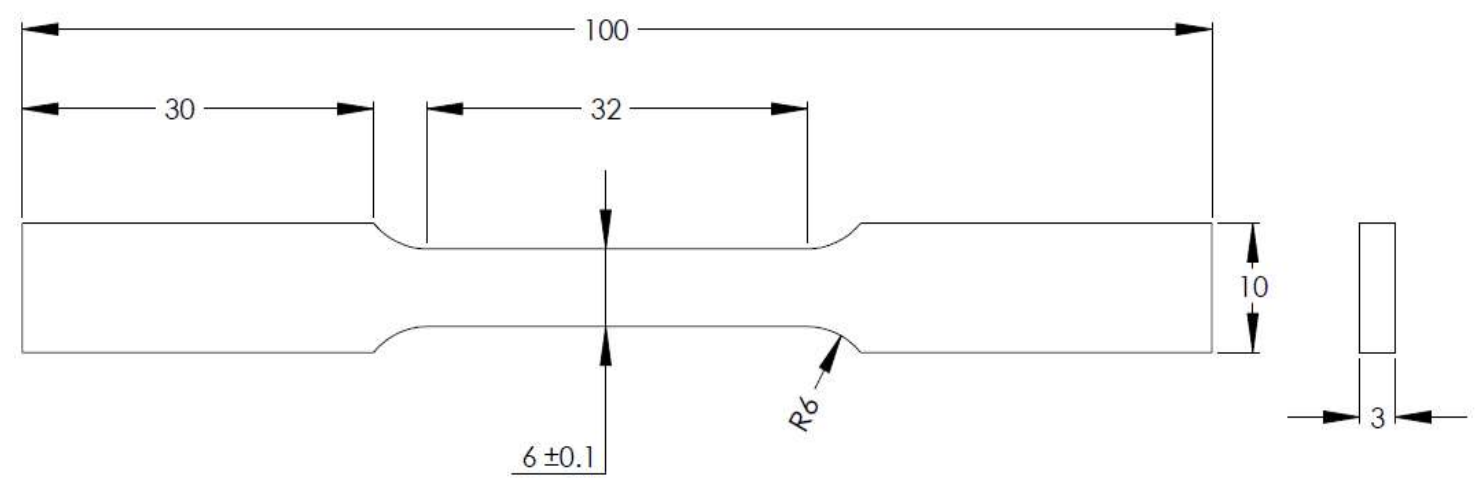

Fig.1.Tensile testing specimen (all dimensions are in $\mathrm{mm}$ )

The compact tension (CT) specimens were prepared in accordance to ASTM E647 [17] with dimensions of width, $\mathrm{W}=50 \mathrm{~mm}$ and thickness, $\mathrm{B}=12 \mathrm{~mm}$ as shown in Fig. 2. The specimens were machined using wire cut EDM (electric discharge machining). A sharp notch, $4 \mathrm{~mm}$ wide was machined by EDM in order to reduce residual compressive stresses that might be evident as a consequence of the milling process [18]

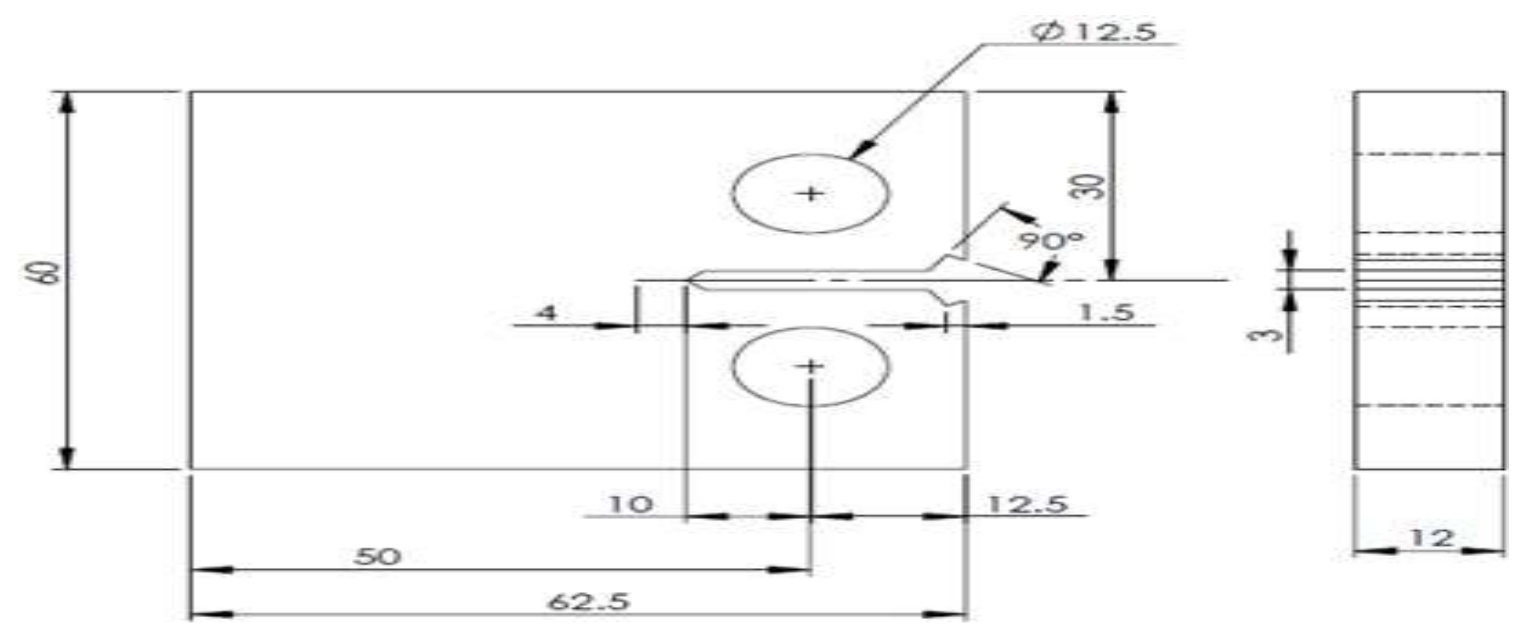

Fig.2.Specimen geometry used for FCG testing (all dimensions are in $\mathrm{mm}$ )

FCG tests were conducted according to ASTM E647 [17] procedures using a servo-hydraulic universal test with a $100 \mathrm{kN}$ capacity load cell. The testing facility was controlled by a computer. All the experiments were performed in an ambient surrounding under a sinusoidal waveform loading frequency of $10 \mathrm{~Hz}$ and with a chosen load ratio of $\mathrm{R}=0.1$. The tests were started with a fatigue pre-cracking process to initiate a crack from the sharp notch of each CT specimen. The importance of the fatigue pre-cracking process is to provide a sharpened fatigue crack of adequate size and straightness. The fatigue pre-cracking was generated by 
applying a value of $\mathrm{K}_{\max }$ set to $32(\mathrm{MPa} . \mathrm{m} 1 / 2)$ with sinusoidal cyclic loading with a load ratio, $\mathrm{R}=0.1$ at a frequency of $10 \mathrm{~Hz}$ until a crack of the desired length appeared. For the present work, a pre-crack length of $0.10 \mathrm{~B}(1.2 \mathrm{~mm})$ was made. After the pre-cracking process, all the specimens were subjected to FCG test under constant amplitude loading conditions until the specimens fractured. The experimental setup for FCG test is shown in Fig. 3. The fatigue crack length of the specimens was measured by using the compliance method by employing a clip gauge at the notch mouth [19].

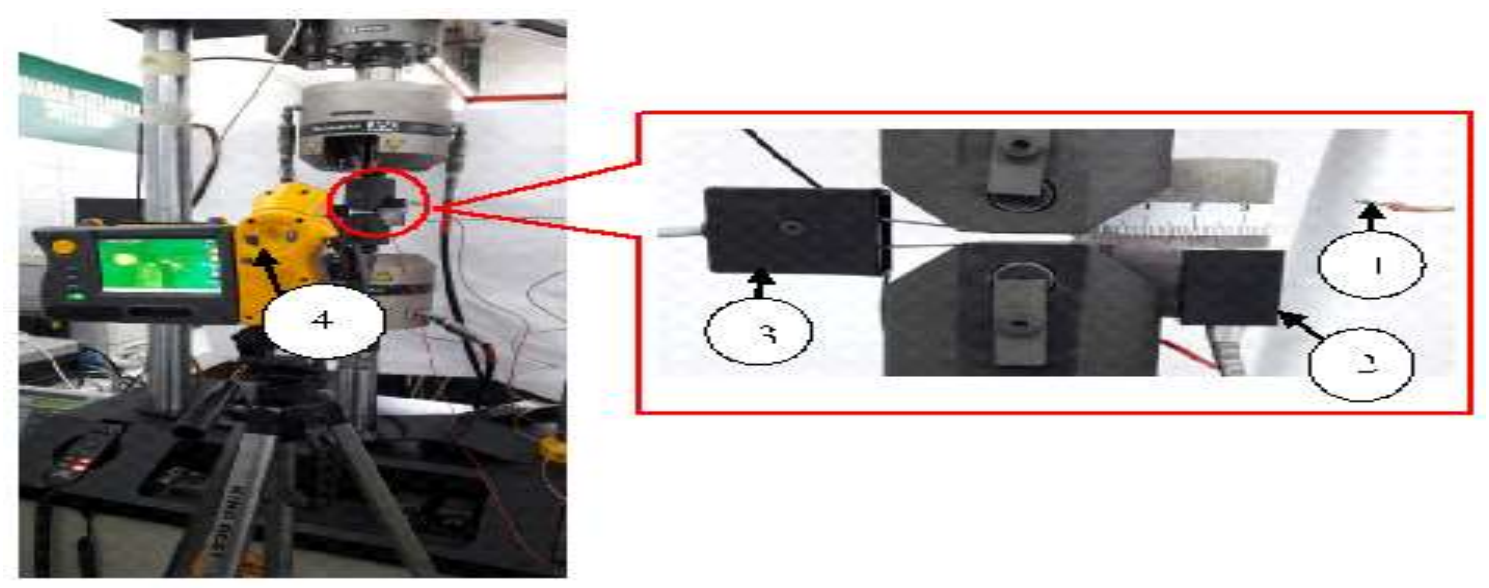

Fig.3.Schematic diagram for FCG test; 1) Thermocouple-measure ambient temperature, 2) Thermocouple-measure temperature of specimen surface, 3) clip gauge, 4) high-resolution infrared (IR) thermal imager

\subsection{Temperature Evolution under Cyclic Loadings}

Two magnetic thermocouples were used to determine the temperature evolution in the test samples. Magnetic thermocouples were employed to mitigate the delamination of a given thermocouples starting at specimen surface while in the test. One thermocouple was employed to record the surface temperature evolution of a given specimen near the crack growth through the FCG test. The other thermocouple was placed close to the specimen to record the ambient temperature making sure that any temperature changes that occur toward the specimen surface would not be influenced by ambient temperature. A National Instrument USB-9211 data acquisition device was used to collect thermocouple data. A high-speed, high-resolution infrared (IR) thermal imager is applied to calibrate the thermocouples initially of a given test, and also to capture the thermal image of the crack growth. The temperature 
was measured towards the crack tip. Resulting from the material's reaction to the unexpected movement, dislocations and defects associate with the surface intrusion and extrusion, the surface temperature increases rapidly at the beginning of the test. An entropy accumulation curve vs. the total number of loading cycles was plotted for the as-received and tempered Fe-C steel specimens throughout the whole FCG test under CAL conditions as shown in Figure 4. A close scrutiny of Figure 4 reveals that the temperature evolution undergoes three distinct phases. Within the first stage, the surface temperature increases rapidly in the beginning of the FCG test. In the second stage, the temperature levels off and become steady. In the third stage, the temperature begins to rise abruptly, and failure of the sample ensues.

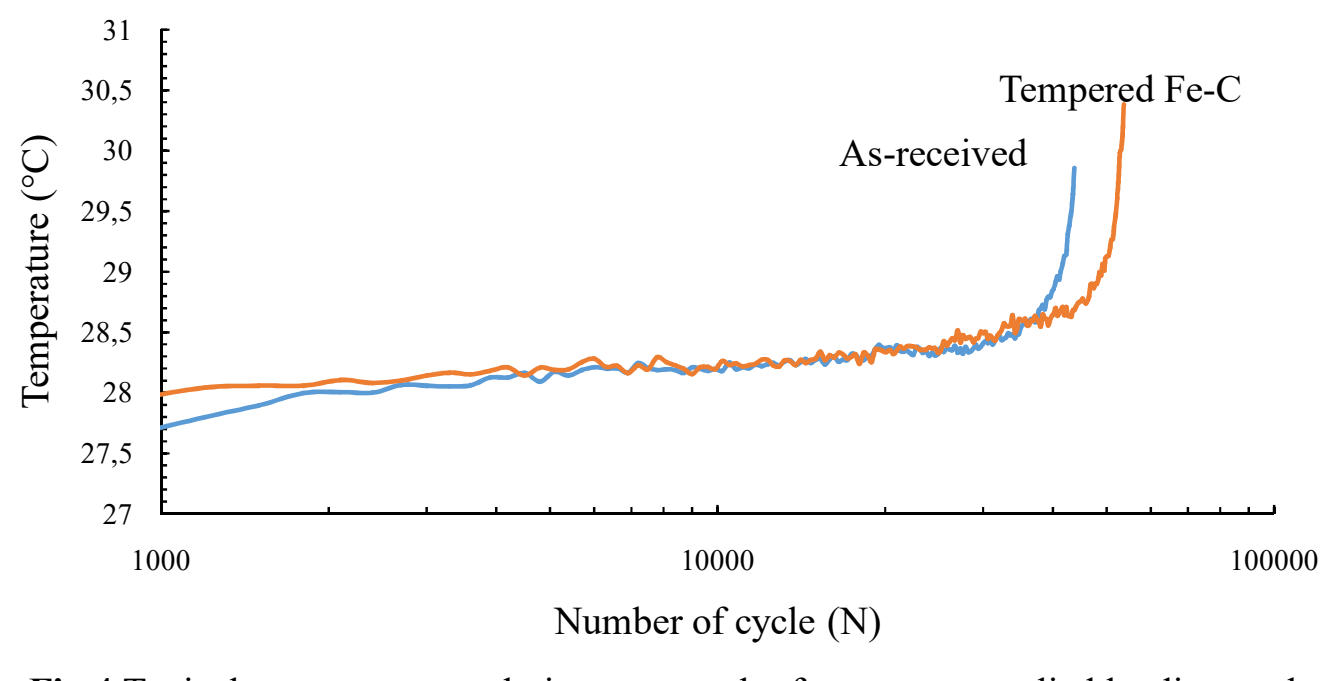

Fig.4.Typical temperature evolution as a result of a constant applied loading cycle

\section{RESULTS AND DISCUSSION}

\subsection{Tensile Properties}

The variation of the mechanical properties for the as-received and tempered $\mathrm{Fe}-\mathrm{C}$ steel specimens are presented in Table 2. The engineering stress-strain curves for the as-received and tempered $\mathrm{Fe}-\mathrm{C}$ steel are given in Fig. 5. It was observed that the ductility values for tempered Fe-C specimens were lower than as-received specimen. This artifact occurs due to the existence of harder and less ductile ferrite matrix in the microstructure of the tempered Fe-C steel samples. The higher ductility observed in the as-received samples is due to the ferrite-pearlite structures being softer than the martensitic structures present in the tempered Fe-C samples. 
It can be seen that the mechanical properties are changed significantly after heat treatment. The yield strength (YS) and ultimate tensile strength (UTS) are increased by heat treated process. The yield and ultimate tensile strength increase rapidly after heat treatment and the growing trend of strength continues and reaches up to $495 \mathrm{MPa}$ and $597 \mathrm{MPa}$ respectively. This indicates that the strength values of the investigated tempered $\mathrm{Fe}-\mathrm{C}$ specimen are higher than the strength of the as-received specimen, due to the presence of the harder second phase in the tempered Fe-C specimens which is martensite [20]. However, it should be noted that the strength of martensite formed in soft ferrite matrix may be different from the structure formed when steel is transformation from austenite to $100 \%$ martensite [21].

Table 2. Mechanical properties of the specimens for all steels

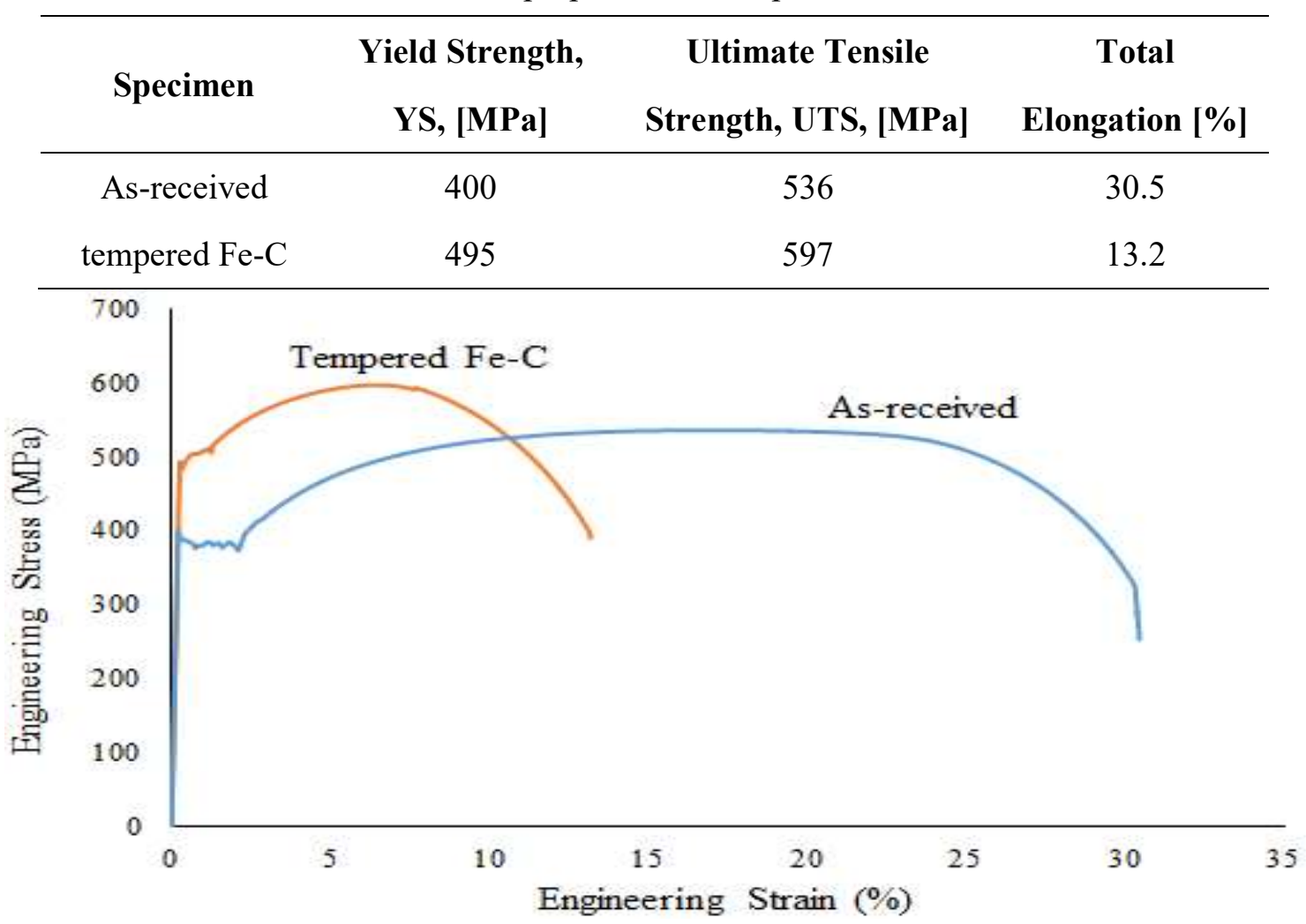

Fig.5.Engineering stress-strain curve for as-received and tempered Fe-C steels.

\subsection{Entropy Generation}

The entire FCG test was calculated in order to get the evolution of entropy generation and then integrated over time from the beginning of the test until the time when fracture occurs as shown below [7]: 


$$
\sigma_{f}=\int_{0}^{t_{f}}\left(\frac{W_{p}}{T}\right) d t(9)
$$

where $\mathrm{T}$ is the surface temperature and $\mathrm{W}_{\mathrm{p}}$ is the cyclic plastic energy per unit volume.

The results of the total entropy generation for the as-received and tempered $\mathrm{Fe}-\mathrm{C}$ steel undergoing loading cycles until failure are plotted in Fig. 6. The total entropy generation is set to be zero at the start of the test, and it increases linearly until it reaches failure. The total entropy generation for as-received steel and tempered Fe-C steel is $10.52\left(\mathrm{MJ} / \mathrm{m}^{3} . \mathrm{K}\right)$ and $27.23\left(\mathrm{MJ} / \mathrm{m}^{3} . \mathrm{K}\right)$ respectively. The variation in value considering the total entropy generation between as-received and tempered $\mathrm{Fe}-\mathrm{C}$ steel is because of the difference in time for failure to occur with different mechanism of FCG due to different microstructures. Other researchers [22-23] have found that the total entropy generation for a given material is not dependent on geometry, load and frequency but is constant at the time of failure. Hence, the entropy generated up to failure can be viewed as a material property [23].

A different total entropy generation can be expected with material with different properties at the fracture point, such as aluminium 6061 and stainless steel 304 with the value of a total entropy generation ranging approximately between $4\left(\mathrm{MJ} / \mathrm{m}^{3} \cdot \mathrm{K}\right)$ and $60\left(\mathrm{MJ} / \mathrm{m}^{3} \cdot \mathrm{K}\right)$ respectively [22-23]. In this research, an interesting observation which can be made is that there are differences within the value of entropy generation amongst as-received and heat treated, tempered $\mathrm{Fe}-\mathrm{C}$ steel because the mechanical properties of the steel was changed due to different microstructures.

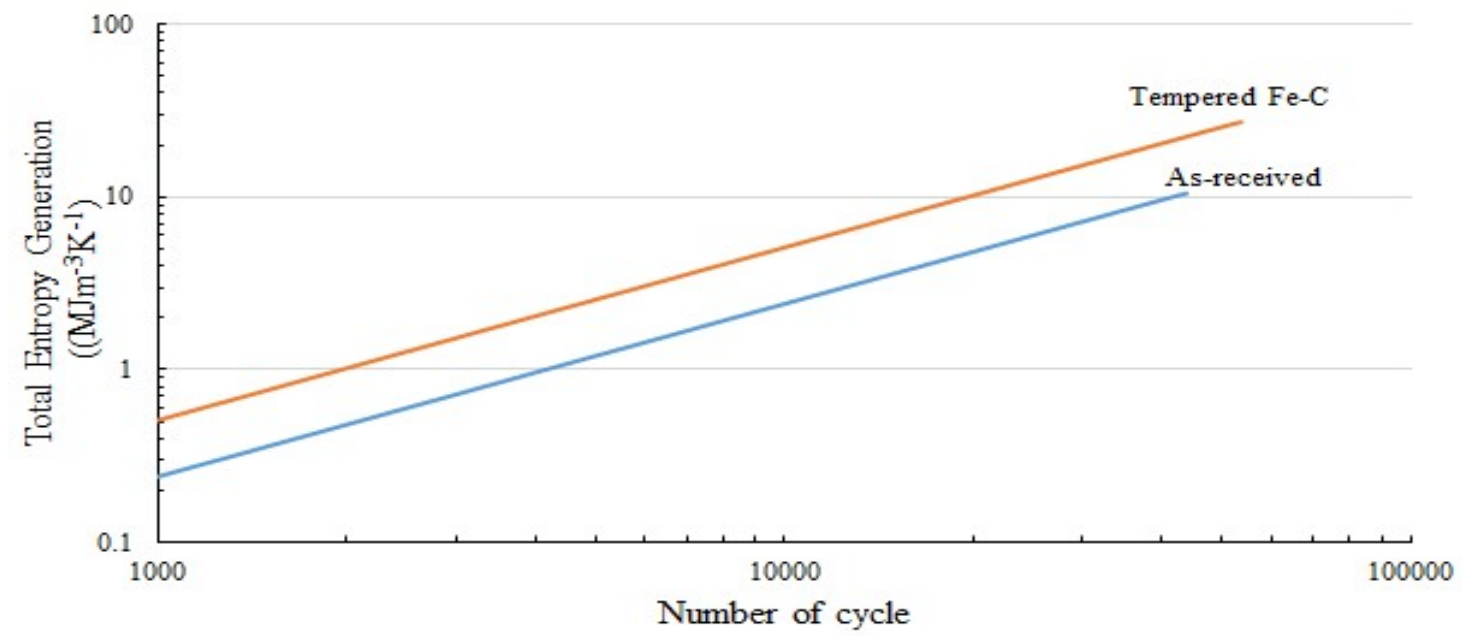

Fig.6.Evolution of total entropy generation for as-received and tempered Fe-C steels 


\subsection{Relationship between Degradation Rate Parameter and Entropy Generation}

As mention before, the crack length was considered as the degradation parameter, $\mathrm{w}=\mathrm{a}$. Based on Equation (2), B measures how entropy generation and degradation interact toward the degree of dissipative process, p. Fig. 7 and 8 show the relation between rate of degradation and rate of entropy generation as correlated with degradation coefficient, B for as-received and tempered $\mathrm{Fe}-\mathrm{C}$ steels. It is clearly show that the degradation rate which is in this case the degradation parameter to be the crack length, da/dt has a linear relationship with the components of entropy generation, $d a / d t=B \sigma$. It can be seen that the as-received steel has lower degradation coefficient, $\mathrm{B}$ as compared to tempered $\mathrm{Fe}-\mathrm{C}$ steel due to the subgrain structure along the grain boundaries which resulting from martensitic lath structure during tempering. It was observed that the steel tempered at high temperature, enhanced recovery considering the subgrain structure along the grain boundaries would be the possible cause of the premature failure and the resulting loss of rupture strength [24]. The interaction between entropy generation and crack growth towards the degree of dissipative plastic deformation process can be measured by the degradation coefficient, B. This degradation coefficient, B is then used to determine the rate of fatigue crack propagation based on the degradation-entropy generation theorem.

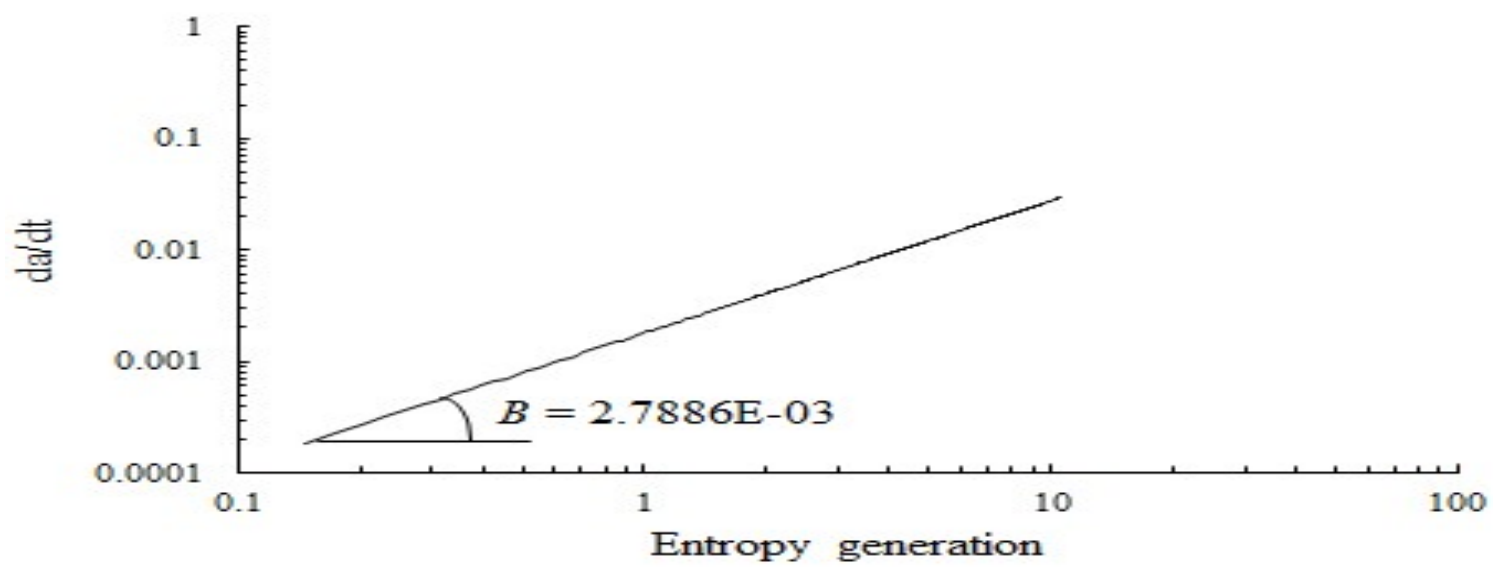

Fig.7.Relationship between rate of degradation parameter and entropy generation for as-received steel 


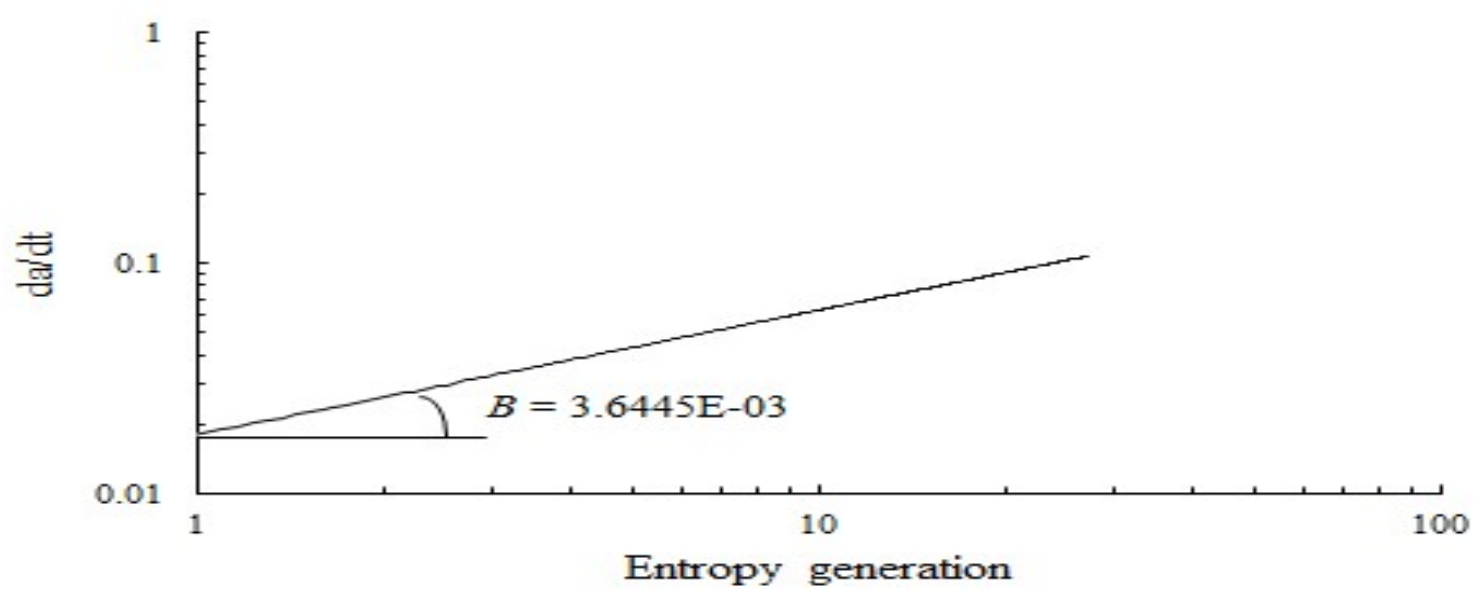

Fig.8. Relationship between rate of degradation parameter and entropy generation for tempered Fe-C

\subsection{Fatigue Crack Growth Rate Prediction}

The crack growth rate model developed from degradation-entropy generation theorem using Equation (7) is then compared with the experimental results for as-received and dual phase material. Comparison of the $\mathrm{da} / \mathrm{dNvs} \Delta \mathrm{K}$ response for experimental data with respect to the present model given by Equation (7) is shown in Fig. 9 and Fig. 10 for the as-received steel and the tempered Fe-C steel, respectively. The calculated Paris constant, $\mathrm{C}$ and $\mathrm{m}$ values of experimental data and present model are given in Table 3. The results show encouraging agreement amongst the present model and the measured crack growth data. The accuracy of the present model with respect to the experimental data was determined by a statistical test of the variance of given residuals i.e. Root Mean Square Error (RMSE). The results show the value of RMSE for as-received steel is $1.5570 \mathrm{E}-06 \mathrm{~m} / \mathrm{cycle}$, while for tempered $\mathrm{Fe}-\mathrm{C}$ steel is $5.1539 \mathrm{E}-07 \mathrm{~m} /$ cycle. This indicates that the present model well-predicts the experimental data for which the measured crack growth data very nearly scales with $\Delta \mathrm{K}^{4}$. In this case, the tempered Fe-C steel has be found to be $\Delta \mathrm{K}^{3.8932}$ which is most nearest to $\Delta \mathrm{K}^{4}$ compared to the as-received steel which is $\Delta \mathrm{K}^{3.2418}$. The predicted results are also in good agreement when using the measured data at mid-range values of $\Delta \mathrm{K}$. Thus, although the predicted slope has very small errors, the Paris regime data throughout the log-log plot looks well-reproduced by the present model. It has to be noted that the model is sensitive to the different mechanism of FCG resulting from different microstructures in material. The source of the minor errors could stem from the solution of a complete coupled thermo-mechanical solution of the problem, 
which we have not done in the present work, and this will be investigated in our future works.

Table 3. Fitting parameters for the experimental data and present model

\begin{tabular}{ccccc}
\hline \multirow{2}{*}{ Material } & \multicolumn{2}{c}{ Experimental Data } & \multicolumn{2}{c}{ Present Model } \\
& $\mathbf{C}$ & $\mathbf{~ m}$ & $\mathbf{C}$ & $\mathbf{m}$ \\
\hline As-received & $4.9736 \mathrm{E}-12$ & 3.2418 & $2.6026 \mathrm{E}-13$ & 3.9961 \\
Tempered Fe-C & $3.2708 \mathrm{E}-13$ & 3.8932 & $2.2210 \mathrm{E}-13$ & 3.9960 \\
\hline
\end{tabular}

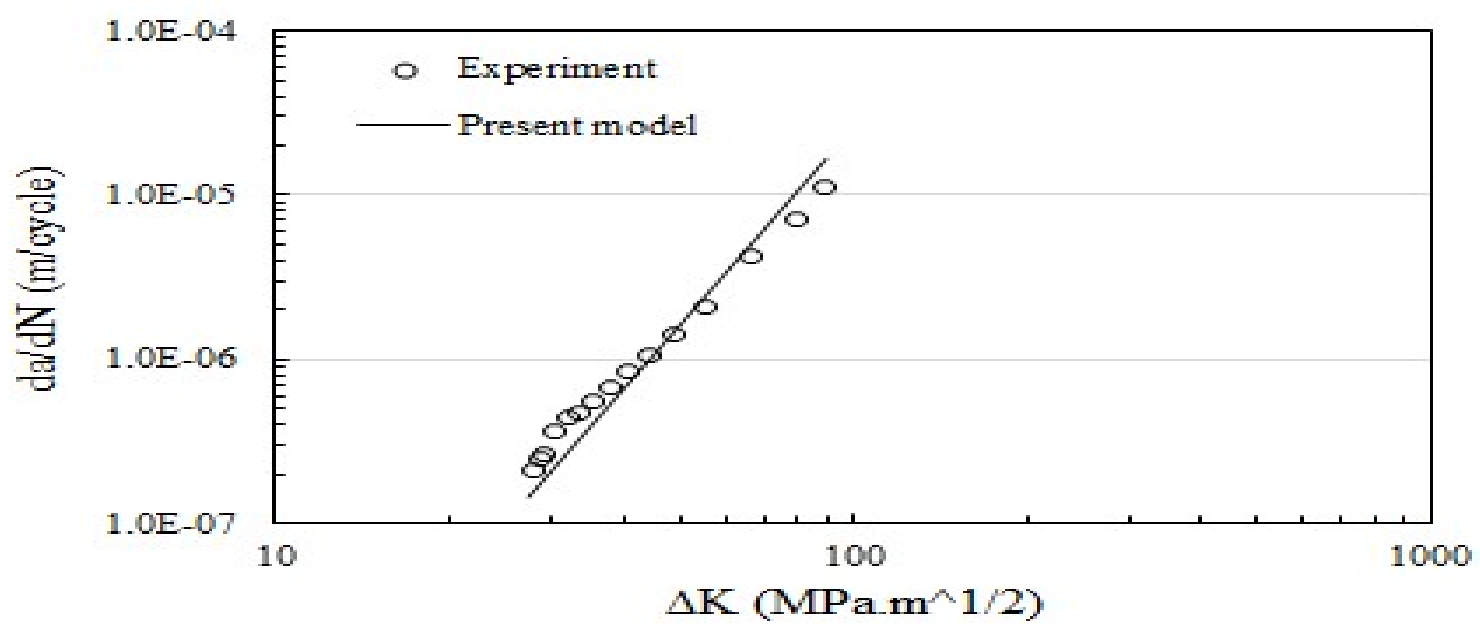

Fig.9.Comparison of the predicted crack growth rate using present model with experimental data for as-received steel

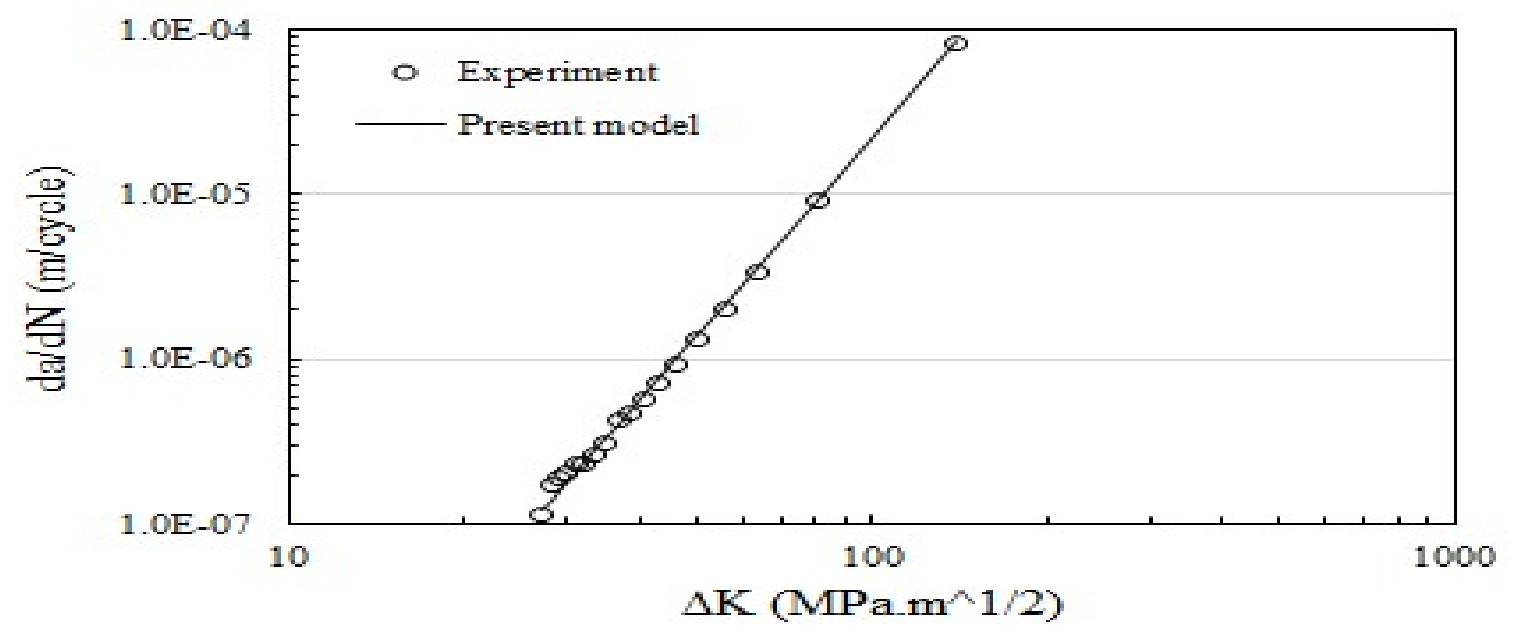

Fig.10.Comparison of the predicted cack growth rate using present model with experimental data for tempered Fe-C steel 


\section{CONCLUSION}

This study presents a comprehension of the physical understanding of entropy generation in tempered Fe-C steel during FCG. An expression for entropy generation in tempered Fe-C steel during FCG in terms of temperature evolution is implemented by using the concept of degradation-entropy generation theorem. Based on degradation-entropy generation theorem, a FCG model is developed to predict the FCG rate. This theorem shows that entropy generation and crack growth are intimately related through degradation coefficient, so that the empirical Paris-Erdogan law of crack growth can easily be found out from consideration of the degradation-entropy generation theorem. The results show that the present model are in good agreement with the experimental results especially for tempered Fe-C steel. The present model is sensitive to the different mechanisms of FCG as a consequence of different microstructures.

\section{ACKNOWLEDGEMENTS}

The authors would like to express their gratitude to Ministry of Higher Education Malaysia via UniversitiKebangsaan Malaysia (UKM) for funding this research. This work was supported using the Prime Impact Fund of UKM under Grant. No. DIP-2015-003.

\section{REFERENCES}

[1] Paris P C. Fracture mechanics and fatigue: A historical perspective.Fatigue and Fracture of Engineering Materials and Structures, 1998, 21(5):535-540

[2] Motoyashiki Y, Brückner FA, Sugeta A. Microstructural influence on small fatigue cracks in a ferritic-martensitic steel. Engineering Fracture Mechanics, 2008, 75(3-4):768-778

[3] Idris R, Prawoto Y. Influence of ferrite fraction within martensite matrix on fatigue crack propagation: An experimental verification with dual phase steel.Materials Science and Engineering: A, 2012, 552:547-554

[4] Thamburaja P, Jamshidian M. A multiscale Taylor model-based constitutive theory describing grain growth in polycrystalline cubic metals.Journal of the Mechanics and Physics of Solids, 2014, 63:1-28

[5] Jamshidian M, Thamburaja P, Rabczuk T. A multiscale coupled finite-element and 
phase-field framework to modeling stressed grain growth in polycrystalline thin films.Journal of Computational Physics, 2016, 327:779-798

[6] Klamecki B E. A thermodynamic model of friction. Wear, 1980, 63(1):113-120

[7] Naderi M, Khonsari M. An experimental approach to low-cycle fatigue damage based on thermodynamic entropy.International Journal of Solids and Structures, 2010, 47(6):875-880

[8] Naderi M, Amiri M, Khonsari M M. On the thermodynamic entropy of fatigue fracture. Proceedings of the Royal Society of London A: Mathematical, Physical and Engineering Sciences, 2009, 466(2114):423-438

[9] Chudnovsky A. Crack layer theory.NASA Contractor Report 174634, Ohio: Case Western Reserve Unlverslty, 1984

[10] Bryant M D, Khonsari M M, Ling F F. On the thermodynamics of degradation. Proceedings of the Royal Society of London. Series A. Mathematical, Physical and Engineering Sciences, 2008, 464(2096):2001-2014

[11] Amiri M, Modarres M. An entropy-based damage characterization. Entropy, 2014, 16(12):6434-6463

[12] KlingbeilN W. A total dissipated energy theory of fatigue crack growth in ductile solids.International Journal of Fatigue, 2003, 25(2):117-128

[13] Zhang Z, Delagnes D, Bernhart G. Ageing effect on cyclic plasticity of a tempered martensitic steel.International Journal of Fatigue, 2007, 29(2):336-346

[14] Tu M, Hsu C, Wang W, Hsu Y. Comparison of microstructure and mechanical behavior of lower bainite and tempered martensite in JIS SK5 steel.Materials Chemistry and Physics, 2008, 107(2):418-425

[15] Li H, Gao S, Tian Y, Terada D, Shibata A, Tsuji N. Influence of tempering on mechanical properties of ferrite and martensite dual phase steel. Materials Today: Proceedings, 2015, 2:S667-S671

[16] ASTM International. ASTM E8/E8M-16a: Standard test methods for tension testing of metallic materials. Pennsylvania:ASTM International Publisher, 2008

[17] ASTM International. ASTM E647-15e1: Standard test method for measurement of fatigue crack growth rates. Pennsylvania: ASTM International Publisher, 2008

[18] RomeiroF, de Freitas M, da Fonte M. Fatigue crack growth with overloads/underloads: 
Interaction effects and surface roughness.International Journal of Fatigue, 2009, 31(11):1889-1894

[19] Sullivan A M, CrookerT W. A crack-opening-displacement technique for length measurement in fatigue crack growth rate testing-Development and evaluation.Engineering Fracture Mechanics, 1977, 9(1):159-166

[20] KumarA, SinghS B, RayK K. Influence of bainite/martensite content on the tensile properties of low carbon dual phase steels. Materials Science and Engineering: A, 2008, 474(1):270-282

[21] MalequeM A, PoonYM, MasjukiHH. The effect of intercritical heat treatment on the mechanical properties of AISI 3115 steel.Journal of Materials Processing Technology, 2004, $153: 482-487$

[22] AmiriM, NaderiM, Khonsari M. An experimental approach to evaluate the critical damage.International Journal of Damage Mechanics, 2011, 20(1):89-112

[23] AmiriM, KhonsariM M. A thermodynamic approach to fatigue damage accumulation under variable loading.Materials Science and Engineering: A, 2010, 527(23):6133-6139

[24] Maruyama K, Sawada K, Koike J I. Strengthening mechanisms of creep resistant tempered martensitic steel. ISIJ International, 2001, 41(6):641-653

\section{How to cite this article:}

Idris R, Abdullah S, Thamburaja P, Omar M Z. Evaluation of fatigue crack growth rate for iron-carbon metals based on degradation-entropy generation theorem. J. Fundam. Appl. Sci., $2017,9(5 S), 526-541$ 